\title{
VEINTE PREGUNTAS SOBRE EUROPA
}

\author{
Carlos TAIBO \\ Universidad Autónoma de Madrid
}

\section{1. ¿QUÉ ES EUROPA?}

Conviene recelar de cualquier asunción que presuma que el de Europa es un concepto marcado por una realidad natural, de tal suerte que, en consecuencia, nos viene dado sin mayor posibilidad de contestación ni de manipulación. Nos hallamos, muy al contrario, ante un artificio en forma de construcción mental imaginada. De resultas, estamos obligados a identificar diferentes visiones de lo que Europa es, acompañadas a menudo de significativas, caprichosas e interesadas exclusiones. Muchas de estas últimas han adquirido carta de naturaleza, por añadidura, en centros de poder -político, económico y cultural- que se han autoatribuido una suerte de monopolio decisorio en la determinación de lo que es, y de lo que no es, Europa. Nada sería más desafortunado que olvidar esta última circunstancia.

\section{2. ¿CUÁLES SON LOS LÍMITES DE EUROPA?}

La condición artificial del concepto de Europa tiene un fiel reflejo en una cuestión concreta: la que se interroga por los límites del continente europeo. Admitamos, en beneficio del argumento, que la respuesta correspondiente no parece plantear problemas mayores en lo que respecta a lo que ocurre en el norte, en el oeste y en el sur de lo que comúnmente se entiende por Europa. No puede decirse lo mismo, en cambio, en lo que atañe a unos límites orientales los Urales, el Cáucaso- que, de nuevo conforme a la convención al uso, separarían a Europa de Asia. La determinación de cuáles han de ser esas fronteras reclama, con toda evidencia, de criterios inequívocamente marcados por prismas ideológicos de uno u otro cariz: como quiera que los límites que nos ocupan no están dados en la naturaleza, hay que hilvanar criterios precisos que, todos ellos discutibles, permitan encarar la respuesta. Una vez liberados de la ilusión de que hay una realidad geográfica que determina sin discusión lo que es Europa, nos vemos en la obligación de echar mano de fórmulas que, para salir del atolladero, invocan el peso, por ejemplo, de presuntos códigos culturales -así, la civilización judeo-cristiana-, de comunidades aparentemente vinculadas por historias afines o, llegado el caso, de prosaicos datos económicos. Estos criterios, que siempre ilustran el vigor de unos u otros intereses, tienen una importancia mayor de la que parece: no se olvide, sin ir más lejos, que con su concurso pue- 
de fundamentarse que un Estado se convierta en candidato a incorporarse a la UE o, por el contrario, se vea despreciado por ésta.

\section{3. ¿ES CORRECTO, Y EN SU CASO SALUDABLE, IDENTIFICAR EUROPA CON LA UE?}

La Unión Europea es un proyecto que ha hecho su aparición de manera reciente y que, en el trecho temporal que ha recorrido, ha acogido a una parte de los países del continente. No es saludable, por tanto, identificar a la UE con Europa, como no lo es inferir que cuando se habla, por ejemplo, de la defensa de la Unión Europea se está hablando, sin más, de la defensa europea. Claro es que no se trata tan sólo de un problema derivado de confundir la parte y el todo: por detrás de este tipo de malentendidos lo que se aprecia es, con frecuencia, el ascendiente de fórmulas impregnadas por un visible etnocentrismo y un manifiesto deseo de exclusión. Al amparo de tales fórmulas parece como si se viniese a sostener que todo lo que no está dentro de la Unión Europea merece ser ignorado o, más aún, debe ser objeto de desprecio en la medida en que su condición reflejaría la incapacidad paralela para reproducir de manera cabal un modelo, el de la propia UE, al que no se atribuyen sino dimensiones saludables.

\section{4. ¿QUÉ PROBLEMAS FUNDAMENTALES HA MOSTRADO HISTÓRICAMENTE LA UE?}

La Unión Europea -en su momento la Comunidad Europea- ha sido hasta el momento, y ante todo, una alianza de cariz económico. Su dimensión políticodemocrática ha tenido, en cambio, un relieve menor y secundario. De resultas, es fácil entender lo que quiere traerse a la memoria cuando se habla de una $E u$ ropa de los mercaderes para dar cuenta de lo que objetivamente ha sido la condición de un proyecto que sólo ha registrado avances significativos, y razonablemente rápidos, en lo que al libre comercio se refiere. La circunstancia que nos ocupa se ha visto acompañada, con todo, por otra: el crecimiento y la consolidación de la UE se han desarrollado al calor de un esquema visiblemente jerárquico, con países que en todo momento han ocupado papeles prominentes así, Francia o Alemania- y otros condenados a asumir cometidos menores. El esquema de jerarquía correspondiente ha acarreado, por lo demás, una notable pervivencia de los diferentes intereses nacional-estatales.

\section{5. ¿NO PADECE LA UE UN GRAVE PROBLEMA DE DÉFICIT DEMOCRÁTICO?}

A menudo se ha subrayado que, en clave histórica de largo aliento, es menester atribuir al proyecto trenzado en torno a la UE una virtud nada desdeñable: ha permitido que toquen a su fin, o al menos que remitan de forma espectacular, viejos flujos de tensión que, como los protagonizados por Francia y Alemania, 
se revelaron a través de dos cruentas guerras de dimensión planetaria. Aunque lo anterior a duras penas puede negarse, cabe preguntarse por lo que la UE ha supuesto en materia de estricta reconstrucción democrática. De nuevo estamos obligados a subrayar que los progresos realizados al respecto han sido menores. Bastará con recordar que el Parlamento Europeo desempeña funciones menores, que la primacía en la toma de decisiones sigue recayendo en los gobiernos de los Estados miembros o, en suma, y sobre todo, que la ciudadanía considera que las instituciones comunitarias se hallan visiblemente alejadas. No parece, por cierto, que la Constitución de la UE que se vislumbra vaya a cancelar los problemas correspondientes.

\section{6. ¿EN QUÉ MEDIDA LA UNIÓN ECONÓMICA Y MONETARIA HA PERMITIDO REENCAUZAR DEBATES CENTRALES RELATIVOS A LA UE?}

El tratado de Maastricht no ha hecho sino ratificar la rotunda primacía que la lógica económica exhibe en la articulación de la UE realmente existente. Lo ha hecho, además, en un sentido claramente vinculado con las propuestas aireadas al calor del discurso neoliberal. Pese a algunos espasmos de última hora, el déficit público cero y las privatizaciones se han convertido en obsesión de las políticas comunitarias, encaminadas a consolidar un espacio económico unificado que dé rienda suelta a una plena libertad en los movimientos de capitales. Resulta significativo, en paralelo, que no se haya pujado por una convergencia que permitiese avanzar en la homologación de capacidades en terrenos como el de las pensiones o el de los servicios sociales. La secuela principal no ha sido otra que una agresión contra los Estados del bienestar cuyos efectos han sido tanto más delicados cuanto más débiles eran aquéllos. La filosofía que inspira el tratado de Maastricht recuerda poderosamente, por lo demás, a aquella que ha marcado, indeleblemente, muchos programas de ajuste del Fondo Monetario Internacional.

\section{7. ¿QUÉ FUTURO CABE AUGURAR A LA UE?}

Las discusiones relativas a una Constitución de la UE -que no una Constitución europea- tienen como transfondo dos grandes cuestiones. Si la primera afecta a la preservación de unas u otras cuotas de poder para los Estados integrantes, la segunda, estrechamente relacionada con la anterior, se pregunta por el futuro a medio plazo y tiene como hitos principales los conceptos de confederación y Estado federal. Uno y otro ilustran el vigor de proyectos muy dispares. Si el primero remite a una situación genéricamente similar a la actual, con el peso de la capacidad de decisión en manos de los Estados miembros y con estructuras comunes más bien débiles, el segundo apunta al forjamiento de un poder conjunto más asentado, en obvio detrimento de los atribuciones hasta hoy 
en manos de los Estados y, acaso, en franco provecho de la consolidación de una instancia de movimientos más claros en la arena internacional. Conviene subrayar que las posibilidades correspondientes a los dos grandes horizontes que nos ocupan no sólo se dirimen en la lógica confrontación que se registra en el interior de la UE: dependen también, en medida no despreciable, de una tesitura planetaria marcada, entre otras cosas, por la hegemonía norteamericana y la globalización neoliberal.

\section{8. ¿SE HAN SUPERADO LOS DISCURSOS PROPIOS DE CADA ESTADO MIEMBRO DE LA UE?}

Es evidente que el despliegue temporal de la Unión Europea no ha arrinconado los discursos nacionales propios de los Estados miembros. Basta con echar una ojeada a las divergencias, a menudo dramáticas, que en el seno de la UE se revelan en relación con grandes contenciosos de la política internacional: la desintegración de Yugoslavia y la agresión norteamericana contra Iraq han hecho que aflorasen diferencias sustanciales entre países que forman parte de una entidad aparentemente unificada. Pero es que en el propio nivel de la opinión pública se hace por momentos evidente que las idiosincrasias nacionales perviven incólumes, cuando no han adquirido un relieve aún mayor que el que mostraban en el pasado. Puede discutirse, eso sí, si la circunstancia que ahora nos interesa configura un fracaso de la UE o, por el contrario, se antoja lógica, cuando no saludable, en la medida en que ilustraría la posibilidad de hacer compatibles un proceso de acercamiento, por un lado, y la preservación de respetabilísimos elementos identitarios, por el otro.

\section{9. ¿NO ES LÓGICO QUE SE VERIFIQUE UN REVIVAL NACIONALISTA DENTRO DE LOS ESTADOS MIEMBROS DE LA UE?}

El revival nacionalista al que asistimos es, en realidad, el producto de dos circunstancias distintas. Por un lado, cabe invocar el peso de un proyecto de construcción comunitaria que se asienta con claridad en los Estados, y no en las naciones; es lógico que quienes se consideran representantes de éstas reaccionen con críticas más o menos severas. Por el otro, y de forma más general, la globalización en curso, con sus flujos homogeneizadores, está provocando también, como respuesta casi refleja, un renacimiento de los movimientos identitarios. No deja de ser, con todo, un asunto controvertido el de la relación entre la UE y lo que llamaremos naciones sin Estado: no se olvide que la primera ha sido contemplada a menudo, desde los nacionalismos que ahora nos interesan, como una tabla de salvación merced a la cual podría sortearse a los Estados miembros o, por mejor decirlo, a los proyectos centralistas que a menudo han inspirado las políticas de éstos. 


\section{0. ¿QUÉ PROBLEMAS ARRASTRAN LOS CANDIDATOS A LA AMPLIACIÓN DE LA UE?}

Sabido es que, si nada lo remedia, en 2004 la UE contará con diez nuevos miembros. Para las elites políticas de los países candidatos, la UE es una especie de faro que deslumbra y que, en consecuencia, impide calibrar virtudes y defectos; ello ha podido traducirse en pautas no siempre inteligentes en lo que respecta a las negociaciones de adhesión. Por lo que se refiere al ciudadano de a pie, la Unión ya no es la bicoca que parecía diez años atrás. Al margen de lo anterior, la renta per cápita del conjunto de los candidatos es del orden del $40 \%$ de la registrada en la UE, con significativas bolsas de pobreza cuyos integrantes son, por lo demás, víctimas de una prolongada acumulación de sacrificios: los reclamados por las reformas aplicadas en el decenio de 1990, los derivados de las exigencias que hoy plantea la UE y los que verán la luz cuando los candidatos deseen incorporarse a la Unión Económica y Monetaria. Bien puede ser que capas enteras de la población se sientan desplazadas y que ello tenga, antes o después, efectos graves en materia de gobernabilidad.

\section{1. ¿QUÉ EFECTO GLOBAL ESTÁ LLAMADA A EJERCER SOBRE LA UE LA AMPLIACIÓN EN CURSO?}

El número de Estados implicados en la ampliación en curso, y la condición comúnmente poco desarrollada -al menos en comparación con la situación que muestran los miembros de la UE realmente existente- de sus economías han estimulado las discusiones relativas a los efectos que un proceso tan delicado está abocado a ejercer. En los debates correspondientes se ha revelado, ante todo, un temor: el de que la ampliación provoque una inquietante desnaturalización de un proyecto, el de la Unión, que correría el riesgo de perder sus señas de identidad iniciales. Es verdad que semejante visión, de nuevo etnocéntrica y conservadora, ignora que la ampliación bien puede ser un suculento negocio para los miembros de la UE hoy existente, de la mano de fórmulas que parecen ratificar viejas jerarquías y, con ellas, el mantenimiento de los candidatos en la periferia, con capacidades de acción, en consecuencia, muy recortadas.

\section{2. ¿QUÉ PUEDE OCURRIR CON LOS PAIÍSES EUROPEOS QUE QUEDAN FUERA DE LA UE?}

Un riesgo aledaño del proceso de ampliación es el que identifica la posibilidad de que ésta consolide la posición de marginación de un puñado de países de la Europa oriental y balcánica que han quedado al margen de las negociaciones con la UE o han visto, en su caso, como éstas se postergaban indeseablemente. En relación con ellos, lo suyo es subrayar que son dos las hipótesis que se manejan. La primera sugiere que el hecho de que, merced a los candidatos que 
ahora se incorporan, en un futuro inmediato los marginados vayan a mantener fronteras con la UE ampliada debe facilitar una relación mucho más fluida con ésta. La segunda entiende, en sentido contrario, que puede aparecer una suerte de muro separatorio que acreciente las distancias y reduzca los flujos de relación. Las cosas como fueren, si los propios candidatos de estas horas están condenados a instalarse en una periferia no demasiado cómoda, es obligado concluir que quienes quedan al margen del proceso correspondiente deben aprestarse a sumar problemas a los muchos que ya registran desde tiempo atrás. El concepto de tercermundización puede ser útil a la hora retratar la situación de algunos de estos países.

\section{3. ¿QUÉ PUEDE OCURRIR CON LAS RELACIONES DE RUSIAY LA UE?}

Rusia es uno más de los grandes problemas pendientes de resolución para la UE. A título provisional más bien parece que nada se está haciendo por encararlo, circunstancia que puede explicarse en virtud de los recelos que el gigante del oriente continental suscita en la UE de resultas de su delicada situación económica y del pésimo registro que muestra en materia de derechos humanos. Claro es que del lado de Moscú no faltan tampoco las quejas con respecto a una Unión que no sólo carece de un proyecto estratégico en lo que a Rusia respecta: la ampliación en curso traba sensiblemente cualquier aproximación entre Bruselas y Moscú, siquiera sólo sea porque la mayoría de sus beneficiarios son países que mantienen una relación histórica tensa con Rusia. Esto al margen, parece fuera de discusión que, al menos con posterioridad a los atentados del 11 de septiembre de 2001, Estados Unidos ha pujado por atraer a Rusia hacia sí, no tanto porque ésta objetivamente interese a Washington como porque a los ojos de los dirigentes norteamericanos conviene mantener a Moscú alejado de la UE. Es evidente que uno de los temores que acosa a Estados Unidos es el que suscita la perspectiva de una macropotencia euroasiática en la que se den cita la riqueza de la UE y las materias primas energéticas y la profundidad estratégica de Rusia.

\section{4. ¿POR QUÉ MARRUECOS, O TURQUíA, SE TOPAN CON OBSTÁCULOS SIN CUENTO EN SU CAMINO HACIA LA UE?}

La indefinición que en último término rodea a la cuestión de qué es y qué no es Europa tiene por efecto principal una paralela indeterminación en lo que atañe a qué Estados pueden plantear sus candidaturas a una eventual incorporación a la UE. Así las cosas, y como ya hemos sugerido, parecen coexistir varios criterios que proporcionan respuestas diferentes a una pregunta tan decisiva. Uno de ellos presume que Europa es, pese a todo, una realidad geográfica, de tal suerte que un país como Marruecos, emplazado en otra realidad llamada África, 
no podría presentar su candidatura a la adhesión; según este criterio, y por su parte, Turquía vería la suya sometida a agrias discusiones, habida cuenta de su doble condición europea y asiática. Otra percepción del problema señala que lo realmente importante es la presencia de rasgos cultural-civilizatorios comunes. Conforme a esta visión, el hecho de que los dos países que nos ocupan beban en las fuentes de una civilización distinta de la judeo-cristiana trabaría poderosamente su posibilidad de sumarse, antes o después, a la UE. Agreguemos un tercer y prosaico criterio, que viene a sugerir que la incorporación de unos u otros Estados debe determinarse con arreglo a su capacidad para dar satisfacción a determinadas exigencias económicas. Esta última querencia -aparentemente más liberal, toda vez que sobre el papel no cierra el camino a nadie- bien puede ser engañosa, en la medida en que las exigencias en cuestión sean a la postre tan extremadamente restrictivas como interesadas.

\section{5. ¿HAY ALGUNA RELACIÓN ENTRE LAS AMPLIACIONES DE LA OTAN Y DE LA UE?}

Parece obligado señalar que el deseo mostrado por las elites dirigentes de algunos países de la Europa central y oriental en el sentido de sumarse a la Organización del Tratado del Atlántico Norte (OTAN) mucho le debe a una circunstancia: la conciencia de que la incorporación a esta última era una suerte de peaje que convenía pagar si aquello a lo que se aspiraba realmente era a acceder a la Unión Europea. Muchos estudios invitan a concluir, por lo demás, que las opiniones públicas de los países afectados, que revelan un apoyo innegable, si bien frío y superficial, a la adhesión a la UE, exhiben en cambio un muy escaso entusiasmo por la OTAN. En un sentido diferente conviene agregar que las sucesivas ampliaciones de esta última -y singularmente la operada en 1997 con Polonia, la República Checa y Hungría como beneficiarios- han sido interpretadas a menudo como una suerte de premio encaminado a rebajar las protestas de quienes pensaban, en los países correspondientes, que la UE se estaba mostrando poco generosa en las negociaciones relativas a su ampliación. A principios del siglo XXI es obligado subrayar, en fin, que la incorporación de países de la Europa central y oriental a la OTAN se ha convertido en un formidable instrumento de presión de Estados Unidos sobre la UE.

\section{6. ¿CUÁL ES LA NATURALEZA DE LA RELACIÓN BILATERAL EXISTENTE ENTRE LA UE Y ESTADOS UNIDOS?}

Carente de un proyecto estratégico propio y con notables divisiones internas, la UE ha mostrado desde mucho tiempo atrás, en lo que a EE.UU. respecta, una línea general de sumisión. Aun con ello, la relación bilateral con el gigante del norte americano suscita de siempre polémicas en el seno de la Unión. Mientras unos se inclinan por una franca colaboración entre las dos instancias que nos 
ocupan, otros reclaman una competición más aguda. Esta última, que ha ido cobrando cuerpo, incipientemente, en el terreno comercial, apenas se ha revelado, sin embargo, en el ámbito estricto de la política exterior y menos aún en el de los hechos militares. A principios del siglo XXI el grupo humano que dirige Estados Unidos se mueve, en lo que atañe a la UE, entre dos grandes percepciones: si la primera habla de un visible desprecio, la segunda refiere, sin más, reticencias varias. Detrás de uno y otras, y al menos a título provisional, la liviandad de los espasmos de independencia del lado de la UE ha hecho que EE.UU. no ahorre esfuerzos para preservar -eventualmente a través de la atracción ejercida sobre determinados miembros de la Unión- una relación bilateral estable que con toda evidencia beneficia a Washington.

\section{7. ¿QUÉ LEGADO CABE ESPERAR QUE SE DERIVE DE LA OPOSICIÓN QUE FRANCIA Y ALEMANIA MOSTRARON, A PRINCIPIOS DE 2003, ANTE UNA AGRESIÓN NORTEAMERI- CANA CONTRA IRAQ?}

La oposición invocada se desvaneció en buena medida una vez que las primeras bombas estadounidenses cayeron sobre Bagdad y tanto Francia como Alemania se abstuvieron de convocar con urgencia el Consejo de Seguridad para promover en su seno una resolución condenatoria. No sólo eso: unos días después París y Berlín estampaban su firma en un documento de la UE que se limitaba a reclamar para la ONU un papel protagonista en la reconstrucción posbélica en Iraq. Semanas después, Francia y Alemania habían cancelado el grueso de sus críticas y parecían inclinarse por participar, de manera más o menos activa, en el negocio que algunos auguraban en el Iraq de posguerra. Si hay que guiarse por los datos que acabamos de manejar, no debe concederse muchas posibilidades a la perspectiva de una renovado proyecto que, en el seno de la UE, coloque a ésta en posición crecientemente independiente con respecto a Estados Unidos. Bien es cierto que, en un sentido contrario, es lícito sugerir que los problemas con que Washington se topó en su relación con aliados prominentes bien pueden traducirse en un comportamiento futuro de EE.UU. más moderado, cauteloso y propicio a la obtención de acuerdos.

\section{8. ¿NO SE VISLUMBRA EN EL FUTURO UNA ABIERTA COMPETICIÓN ENTRE EL EURO Y EL DÓLAR?}

Al calor del ataque contra Iraq, en marzo de 2003, ha reaparecido una tesis que invoca la existencia de una dura y soterrada competición entre las monedas propias de Estados Unidos -el dólar- y de la mayoría de los miembros de la UE -el euro-. Lo cierto es que, pese a que en los momentos iniciales de su recorrido el euro experimentó cierto retroceso con respecto al dólar, con posterioridad ha ido recobrando peso, y ello tanto en términos de cotización como de presencia 
en los mercados internacionales. A los ojos de muchos expertos, es significativo cómo la moneda europea ha irrumpido, en particular, en las transacciones relativas a materias primas energéticas. En este marco, el ataque estadounidense contra Iraq habría respondido, en una de sus claves, al propósito de cortocircuitar las posibilidades del euro. Aunque algo pueda haber de cierto en ello, y aunque, a buen seguro, la competición que invocamos parezca llamada a ganar relieve, lo cierto es que en 2003 los perfiles de esa colisión se antojaban un tanto desvaídos. Recordemos, por ejemplo, que el relativo éxito de la operación norteamericana en Iraq no se saldó con problemas evidentes para el euro. Subrayemos, por otra parte, que la condición de los agentes políticos que aparentemente están por detrás de las monedas enfrentadas es difusa: hay muchos capitales estadounidenses invertidos en euros, de la misma suerte que hay muchos capitales europeos invertidos en dólares. Esto al margen, no es sencillo explicar el comportamiento de un puñado de miembros de la UE -unos han optado por dotarse del euro como moneda de curso legal; otros permanecen al margen de él- que han apoyado sin cautela la agresión de EE.UU. contra Iraq. La sugerencia, en fin, de que detrás del euro se hallaría un modelo de capitalismo productivo enfrentado a otro, el del dólar, de capitalismo especulativo se antoja demasiado simplificadora, por mucho que algunos datos vengan a justificarla.

\section{LA GESTACIÓN DE UNA POTENCIA EUROPEA, ¿PASA NECESARIAMENTE POR UN ACRECENTAMIENTO DEL GASTO MILITAR DE LOS ESTADOS PARTÍCIPES?}

Un buen termómetro de lo que está llamada a ser la UE es el que se propone calibrar las dimensiones de su gasto militar futuro. Conviene adelantar, con todo, que las mediciones correspondientes pueden conducir a conclusiones extremadamente dispares. Conforme al criterio más común, si la UE desea acrecentar sensiblemente su independencia con respecto a Estados Unidos, tendrá que dotarse inevitablemente de una poderosa maquinaria militar, más o menos unificada. De acuerdo con un criterio muy distinto que merece, sin embargo, atención, hay que preguntarse si el asentamiento de un proyecto soberano del lado de la UE no debe pasar, de modo necesario, por el forjamiento de políticas que antes que asentarse en una activa militarización lo que reclamen sea un proceso de signo contrario. Si se trata de mencionar un ejemplo al respecto, con arreglo a esta segunda perspectiva el encaramiento de las presuntas amenazas que la UE tiene presumiblemente que encarar en el conjunto del mundo árabe su periferia meridional- debe reclamar el concurso de políticas mucho más vinculadas con la cooperación económica, social y cultural que con el fortalecimiento de las capacidades militares al uso. El vigor de esa cooperación puede convertirse en un indicador mucho más sólido de una proyecto independiente 
del estadounidense que el que proporcionaría un gasto en defensa sensiblemente acrecentado.

\section{HOY POR HOY, ¿ES CLARAMENTE DISTINTO EL MODELO PROPIO DE LA UE DE AQUEL QUE HA ADQUIRIDO CARTA DE NATURALEZA EN EE.UU.?}

Los modelos de la UE y de EE.UU. se antojan más similares de lo que determinada mitología ha venido a sugerir. Por lo pronto, y en el terreno de la economía, dos decenios de políticas neoliberales han hecho que los elementos caracterizadores de un capitalismo social europeo hayan ido remitiendo en provecho de los que impregnan a otro capitalismo, el norteamericano, mucho más marcado por una competición descarnada. En un terreno distinto, el de las relaciones exteriores, conviene deshacerse de cierta retórica que sugiere que, como por arte de magia, la UE está llamada a desenvolverse en la arena planetaria en franco compromiso con la causa de la justicia, la paz y la solidaridad. Un simple repaso de la condición personal de las figuras que encabezan la mayoría de los Estados miembros de la UE invita a recelar de semejante percepción. Y ello es así aun cuando resulte obligado reconocer los efectos moderadamente saludables, y paradójicos, de una interesante circunstancia: la división que sigue dejando su impronta en la condición propia de la UE -a los ojos de muchos un mal en sí mismo- ha tenido la virtud de desdibujar eventuales espasmos imperialcoloniales del lado de esta última.

RESUMEN: Las líneas que siguen acogen un puñado de reflexiones que, a vuela pluma, se proponen encarar algunos de los problemas que acosan a una realidad evanescente, Europa, en cuyo seno ha cobrado cuerpo una instancia dotada de perfiles muy materiales: la Unión Europea (UE). Pese a que el formato del texto -preguntas y respuestasbien puede sugerir que éste responde a un propósito fundamentalmente pedagógico, la línea maestra que discurre por detrás es otra y remite, antes bien, a una toma de posición que invita a analizar con escepticismo, y en su caso con franca voluntad de rechazo, muchos de los elementos que participan en la configuración contemporánea de Europa y de la Unión Europea.

PALABRAS CLAVE: Límites de Europa; Unión Europea; Déficit democrático; Ampliación.

ABSTRACT: The lines that continue welcome a handful of reflections that, to feather it flies, they intend to be faced some of the problems that harass to an evanescent reality, Europe in whose breast has charged body an instance endowed with very material profiles: the European Union (UE). in spite of the fact that the format of the text -questions and answers- well he can suggest that this responds to a fundamentally 
pedagogic purpose, the line teacher that she reflects from behind is other and it remits, before well, to one taking of position that invites to analyze with scepticism, and in its case with frank will of rejection, many of the elements that participate in the contemporary configuration of Europe and of the European Union.

KEY WORDS: European Borders; European Union; Democratic Shortage; Enlargement.

$\boldsymbol{R E} \boldsymbol{E} \boldsymbol{U} \boldsymbol{M E}$ : Les lignes suivantes abordent à brûle-pourpoint un ensemble de réflexions sur quelques-uns des problèmes auxquels se trouve confrontée une réalité évanescente, l'Europe, qui a vu naître en son sein une entité avec un profil bien défini : l'Union européenne (UE). Bien que la structure du texte, sous forme de questions et réponses, pourrait faire penser à une finalité pédagogique, elle appelle à une prise de position invitant le lecteur à analyser avec scepticisme de nombreux facteurs participant à la configuration actuelle de l'Europe et de l'Union européenne et, le cas échéant, à les refuser.

MOTS-CLÉS: Frontières de l'Europe, Union européenne, déficit démocratique, élargissement.

RESUMO: As linhas que se seguem acolhem um punhado de reflexões as quais, a voo de pássaro, se propõem encarar alguns dos problemas que acossam uma realidade evanescente, Europa, em cujo seio tem criado corpo uma instância dotada de perfis muito materiais: a União Europeia (UE). Apesar de que o formato do texto -perguntas e respostas- pode bem sugerir que este responde a um propósito fundamentalmente pedagógico, a linha mestra que decorre por detrás é outra e remete, antes assim, a uma tomada de posição que convida a analisar com cepticismo, e em todo o caso com franca vontade de rechaço, muitos dos elementos que estão a participar da configuração contemporânea da Europa e da União Europeia.

PALAVRAS CHAVE: Limites da Europa; União Europeia; Défice democrático; Ampliação. 